CLINICAL STUDY

\title{
Identification and functional characterization of a missense mutation in resistin in two patients with severe obesity and insulin resistance
}

Sigri Beckers, Fenna de Freitas, Doreen Zegers, An Verrijken ${ }^{1}$, Armand V Peeters, Frida Peiffer ${ }^{1}$, Stijn L Verhulst ${ }^{2}$, Guy Massa ${ }^{3}$, Ilse L Mertens ${ }^{1}$, Kristine N Desager ${ }^{2}$, Luc F Van Gaal ${ }^{1}$ and Wim Van Hul

Department of Medical Genetics, University of Antwerp, Universiteitsplein 1, B-2610 Antwerp, Belgium, ${ }^{1}$ Department of Endocrinology, Diabetology and Metabolism, Antwerp University Hospital, Wilrijkstraat 10, 2650 Antwerp, Belgium, ${ }^{2}$ Department of Paediatrics, Antwerp University Hospital, Wilrijkstraat 10, 2650 Antwerp, Belgium and ${ }^{3}$ Department of Paediatrics, Jessa Hospital, Stadsomvaart 11, 3500 Hasselt, Belgium

(Correspondence should be addressed to W Van Hul; Email: wim.vanhul@ua.ac.be)

\begin{abstract}
Objective: In this study, we hypothesized that mutations in the resistin encoding gene, RETN, may cause a monogenic form of obesity.

Design/methods: We screened the coding region of RETN in 81 morbidly obese adults, 263 overweight and obese children/adolescents, and 116 healthy lean subjects. In vitro experiments include qPCR, ELISA, and western blot for WT and mutant resistin transfected into 3T3-L1 adipocytes.

Results: Mutation analysis identified five sequence variants in our patient populations: $3^{\prime}$-UTR +87 G/A, 3'-UTR + $100 \mathrm{~A} / \mathrm{G}, \mathrm{T} 73 \mathrm{~T}, \mathrm{IV3}-61 \mathrm{C} / \mathrm{A}$, and C78S. In our control population, we only found the $3^{\prime}$-UTR $+87 \mathrm{G} / \mathrm{A}$ variant. We started functional experiments for the C78S mutation that was found in a 20-year-old obese male (body mass index $(\mathrm{BMI})=39.7 \mathrm{~kg} / \mathrm{m}^{2}$ ) and his obese mother $\left(\mathrm{BMI}=31.9 \mathrm{~kg} / \mathrm{m}^{2}\right)$. In vitro testing demonstrated that the mutation does not impair mRNA expression. We identified a 100-fold lower extracellular protein concentration for mutant resistin compared with WT levels using a resistin ELISA on cell culture medium $\left(P=4.87 \times 10^{-6}\right)$. We also detected a decreased intracellular concentration for the mutant protein (tenfold lower relative levels, $P=0.007)$. The plasma resistin levels of the proband and his mother, however, did not differ significantly from lean control individuals.

Conclusions: In conclusion, we identified the first missense mutation in resistin in a morbidly obese proband and his obese mother. Functional testing of the mutant protein suggests that the C78S mutant protein is degraded, possibly resulting in a decreased extracellular concentration, which may predispose to obesity.
\end{abstract}

European Journal of Endocrinology $164927-936$

\section{Introduction}

Resistin is one of the most controversial adipokines. After its initial discovery in mice, resistin was thought to be the link between obesity and diabetes (1-3). This was suggested because of the reported expression and secretion of resistin by adipocytes and because of the increased concentration of the protein in mice with diet-induced and genetic forms of obesity. Furthermore, it was seen that administration of resistin impaired glucose tolerance and increased insulin resistance (IR) in mice. Neutralization of endogenous resistin by antibodies improved insulin sensitivity in mice with diet-induced obesity (1). An inhibitory effect of resistin on adipose conversion could also be demonstrated in vitro $(3,4)$. In addition, it was also suggested that resistin may be involved in inflammation due to its homology to FIZZ1 (2). Further studies demonstrated that lowering resistin levels in high fat-fed mice to levels of mice fed a standard chow can completely reverse IR in these animals (5). Resistin knockout mice have reduced blood glucose levels after fasting and are more glucose tolerant when fed a high-fat diet (6). In mice overexpressing resistin, the high levels of the protein cause glucose intolerance, hyperinsulinemia, and hypertriglyceridemia accompanied by whole-body IR (7). Transgenic mice overexpressing dominant inhibitory resistin show increased adiposity and enlarged adipocyte size (4). Together, these results demonstrate that resistin is involved in obesity and IR in rodents.

As homology between mouse and human resistin is low (only $55.8 \%$ on protein level), it is not surprising that the role of resistin in humans is less clear. Although resistin is predominantly expressed in adipocytes in mice, its expression in humans is most abundant in 
mononuclear cells/macrophages $(8,9)$. In obesity, it has been shown that macrophages infiltrate the adipose tissue $(10,11)$ and this could therefore explain the reports of resistin expression in adipose tissue. Furthermore, serum levels of obese humans were found to be higher than those in lean control subjects $(12,13)$. Other reports, however, did not find any relationship between resistin serum levels, body weight, and obesity $(14,15)$. Several genetic studies have focused on the possible association between resistin polymorphisms and phenotypes of obesity or IR. We previously reported that we found no association of SNPs in RETN with complex obesity in women (16). These results were in line with association studies in other populations $(17,18)$. Some studies, however, reported that SNPs in resistin were associated with higher body mass index (BMI) or other obesity parameters $(19,20)$. Other studies have shown that resistin variants may have a role in the development of type 2 diabetes $(20,21)$, although these associations were not confirmed by others $(22,23)$. This clearly shows that the role of resistin in humans and its possible involvement in obesity and associated IR remains controversial.

Until now, no mutations in human resistin have been reported. In a strain of diet-resistant rats, an L9V mutation in the signal sequence of resistin was described. This mutation did not affect protein secretion as mutant resistin was detected in the culture medium of transfected 3T3-L1 cells. However, differentiation of 3T3-L1 adipocytes expressing mutant resistin was inhibited in vitro, although WT resistin stimulated adipoconversion in these experiments (24).

In this study, we hypothesized that mutations in resistin may be involved in the development of obesity. Discovery of such a mutation would enhance our understanding of resistin's role in humans.

\section{Research design and methods}

\section{Study populations}

Totally, 263 overweight and obese children and adolescents (98 boys and 165 girls; Table 1) were recruited from the Antwerp University Hospital and Virga Jesse Hospital, Hasselt. The young patient

Table 1 Characteristics of study populations. Mean \pm S.E.M. is given for every parameter. Body mass index (BMI) $z$-score based on Flemish Growth Charts (30) is shown only for children and adolescents.

\begin{tabular}{lllll}
\hline & Adults & Children & Adolescents & Controls \\
\hline$n$ & 81 & 87 & 176 & 116 \\
Men/women & $14 / 67$ & $36 / 51$ & $62 / 114$ & $14 / 102$ \\
Age (years) & $43.6 \pm 1.2$ & $8.9 \pm 0.2$ & $15.9 \pm 0.2$ & $38.8 \pm 0.9$ \\
BMl (kg/m $\left.{ }^{2}\right)$ & $47.8 \pm 0.5$ & $28.2 \pm 0.5$ & $35.0 \pm 0.4$ & $22.6 \pm 0.2$ \\
BMl $z$-score & - & $+2.7 \pm 0.1$ & $+2.5 \pm 0.0$ & - \\
\hline
\end{tabular}

population has a mixed ethnicity, which may have an effect on resistin expression as previously reported $(25,26)$. A population of 81 morbidly obese Caucasian adults was recruited from the Antwerp University Hospital outpatient obesity clinic. A control population of 116 lean Caucasian subjects was also included (BMI between 18.5 and $25 \mathrm{~kg} / \mathrm{m}^{2}$; Table 1). All participants gave their written informed consent. The study protocol was approved by the local ethics committee.

\section{Anthropometry}

Height was measured to the nearest $0.5 \mathrm{~cm}$ and body weight was measured with a digital scale to the nearest $0.1 \mathrm{~kg}$. BMI was calculated as weight $(\mathrm{kg})$ over height (m) squared $\left(\mathrm{kg} / \mathrm{m}^{2}\right)$.

\section{Laboratory analyses}

A fasting blood sample was taken for analyses. Plasma glucose, total cholesterol, high-density lipoprotein (HDL) cholesterol, triglycerides, $\gamma$-glutamyltransferase, and uric acid were measured on the Vitros 5.1 FS Chemistry System (Ortho-Clinical Diagnostics, Rochester, NY, USA). Low-density lipoprotein (LDL) cholesterol was calculated with the Friedewald formula (27). Highsensitive C-reactive protein (CRP) was determined on a BN II analyzer (Siemens, Munchen, Germany). Insulin and C-peptide levels were measured on a Modular E170 system (Roche Diagnostics). IR was estimated using the homeostatic model assessment of IR (HOMA-IR) (28). HOMA-IR was calculated as (insulin in $\mu \mathrm{U} / \mathrm{ml} \times$ glucose in $\mathrm{mmol} / \mathrm{l}) / 22.5$, with 1 as a reference value.

\section{Mutation analysis}

We analyzed the coding region of RETN (exons 2-4) and part of the $3^{\prime}$-UTR. Exon 2, exon 3, and the respective intron-exon boundaries were screened using denaturing HPLC (DHPLC) or high-resolution melting curve analysis (HRM). DHPLC was performed on a WAVE Nucleic Acid Fragment Analysis System (Transgenomic, Inc., Glasgow, UK). HRM was performed using the Lightcycler LC480 Real-Time PCR System (Roche) with incorporation of LCGreen + fluorescent dye (Idaho Technology, Inc., Salt Lake City, UT, USA) into the PCR product. Samples with chromatograms or melting curves deviating from WT were sequenced. Due to the presence of several polymorphisms in the amplicon containing exon 4, this exon and the respective intron/exon boundaries were checked using direct sequencing. Sequencing was performed with ABI BigDye Terminator v1.1 Cycle Sequencing kits on an ABI Prism Genetic Analyzer 3130xl (Applied Biosystems, Inc., Foster City, USA). The melanocortin-4 receptor gene $(M C 4 R)$ was screened as described before (29). Primer sequences for mutation analysis of RETN are as follows: exon 2 DHPLC forward 5'-gTTcccTcTTTcAgcgecTgc-3' 
and reverse 5'-gTgccAgggATcAgTgAggTcT-3', exon 2 HRM forward $5^{\prime}$-ATccAgcTgTgggTcTcTTggT- $3^{\prime}$ and reverse $5^{\prime}$-TTggggAgcTTgcccAAgTgg- ${ }^{\prime}$, exon 2 sequencing forward $5^{\prime}$-gTccAggggcAgATccTAc- $3^{\prime}$ and reverse 5'-gTggATAAggTggggAcAgT-3', exon 3 DHPLC forward $5^{\prime}$-cTgTcTccTTTccTccTgccc-3' and reverse $5^{\prime}$-ggAcAAcAgTcTcc-TgcAcTcAc- $3^{\prime}$, exon 3 HRM forward $5^{\prime}$-cTgTcTccTTTccTccTgccc- $3^{\prime}$ and reverse $5^{\prime}$-ggAcAAcAgTcTccTgcAcTcAc- $3^{\prime}$, exon 3 sequencing forward 5'-cTccAAAAcAcccAAcTcAAg- $3^{\prime}$ and reverse $5^{\prime}$-gAgTgAgggTggAcAccAg-3', exon 4 sequencing forward $5^{\prime}$-cAcTggTgTccAcccTcAc-3' and reverse 5'-cAgTTggAgAccccATAggA- $3^{\prime}$.

\section{Cell culture}

3T3-L1 cells were maintained in DMEM supplemented with $10 \%$ FCS, 100 units $/ \mathrm{ml}$ penicillin, $100 \mu \mathrm{g} / \mathrm{ml}$ streptomycin, and $0.25 \mu \mathrm{g} / \mathrm{ml}$ amphotericin B (basal medium; Invitrogen). Cells were incubated at $37^{\circ} \mathrm{C}$ in humidified air containing $5 \% \quad \mathrm{CO}_{2}$. To stimulate differentiation to adipocytes, cells were allowed to grow to confluency. After 2 days' confluency, differentiation was induced by adding $5 \mu \mathrm{g} / \mathrm{ml}$ insulin (Sigma-Aldrich), $0.25 \mu \mathrm{M}$ dexamethasone (Alexis Biochemicals, Lausen, Switzerland), and $0.5 \mathrm{mM}$ iso-butyl-methyl-xanthine (Sigma-Aldrich) to basal medium. After 2 days, this medium was renewed. On day 4 after inducing differentiation, medium was changed to basal medium supplemented with $5 \mu \mathrm{g} / \mathrm{ml}$ insulin. From day 6 , cells were cultured in basal medium until transfection. Medium was renewed every 2 days. Differentiation was visually checked after staining with Oil Red $O$ using a Lipid Staining kit (Zen-Bio, Research Triangle Park, NC, USA).

\section{Vectors}

Wild-type resistin cDNA cloned in a pCMV6-XL4 expression vector and an empty pCMV6-XL4 expression vector were obtained from Origene Technologies (Rockville, MD, USA). Mutant resistin carrying a C78S mutation was created using a Quikchange II Site Directed Mutagenesis kit (Stratagene, USA). All cloned products were sequenced as described above. A pEGFPN1 mammalian expression vector (Clontech) was used as internal control in all transfection experiments.

\section{Transfection}

3T3-L1 adipocytes were transfected on day 12 of differentiation. Cells $\left(2 \times 10^{6}\right.$ cells/transfection $)$ were co-transfected with $2 \mu \mathrm{g}$ WT or mutant resistin in pCMV6-XL4 expression vector and $2 \mu \mathrm{g}$ pEGFP-N1, as internal control. Transfection was performed using the Nucleofector II device with Cell Line Nucleofector solution L according to the manufacturer's protocol (Amaxa, Germany). After transfection, cells were cultured in 24-well plates $\left(5 \times 10^{5}\right.$ cells/well $)$ and incubated for $24 \mathrm{~h}$ before other assays were performed.

\section{EGFP measurement}

EGFP fluorescence was measured with a Wallac Victor ${ }^{2}$ Multilabel Plate Reader (Perkin Elmer, Waltham, MA, USA) $24 \mathrm{~h}$ after transfection. Fluorescence measurements of $1 \mathrm{~s}$ per well were obtained. These measurements were used to determine transfection efficiency (30).

\section{Total protein measurement}

The total amount of protein in cell lysates was determined by BCA Protein Assay (Pierce Biotechnology, Rockford, IL, USA) according to the manufacturer's instructions. Pre-diluted BSA was used as a standard (Pierce Biotechnology). Absorbance at $562 \mathrm{~nm}$ was measured by a Wallac Victor ${ }^{2}$ Multilabel Plate Reader (Perkin Elmer).

\section{Resistin mRNA expression}

RNA was isolated from transfected 3T3-L1 adipocytes $24 \mathrm{~h}$ after transfection. RNA isolation and cDNA synthesis was performed using a TaqMan Gene Expression Cells-to-Ct Kit (Applied Biosystems, Inc.). Expression analysis was performed with TaqMan Gene Expression assays (Applied Biosystems, Inc.) according to manufacturer's protocol. The RETN transcription levels were normalized by three stably expressed reference genes (GAPDH, UBC, and ACTB). The following assays were used: RETN, Hs00982492_g1; GAPDH, Mm99999915_g1; UBC, Mm01201237_m1; ACTB, Mm01205647_g1. Real-time PCR was performed on a Lightcycler LC480 Real-Time PCR System. We compared 14 WT samples with 14 mutant samples. Every run contained a no-template control and all samples were analyzed in duplex. Raw data were imported into the relative quantification software qBase (31) for further analysis. A Mann-Whitney $U$ non-parametrical test was used to check the statistical significance $(P<0.05)$ of the obtained results (SPSS, Inc., Version 15.0, Chicago, IL, USA).

RNA from patients carrying the RETN mutation was isolated from blood collected in PAXgene Blood RNA Tubes using the PAXgene Blood RNA kit according to the manufacturer's protocol (PreAnalytiX, Hombrechtikon, Switzerland). cDNA was synthesized using the SuperScript III First-Strand Synthesis System for RT-PCR with random hexamers (Invitrogen).

PCR on cDNA was performed with primers specific for human resistin mRNA (sequences available on request) using standard conditions. Resulting PCR products were sequenced according to the protocol described above to determine whether the mutant mRNA is expressed. 


\section{Resistin protein expression}

Detection of WT and mutant resistin protein in cell lysates and conditioned media from transfected 3T3-L1 cells was carried out by western blotting. Samples were separated by electrophoresis on $4-20 \%$ polyacrylamideSDS gels under reducing conditions. The proteins were transferred to PVDF membranes by semi-dry transfer and blocked overnight with 5\% (w/v) skimmed milk. Membranes were blotted with polyclonal rabbit antiresistin antibody (1:5000 dilution; Abcam, Cambridge, UK), followed by goat anti-rabbit IgG HRP conjugate (1:10 000; Bio-Rad). After incubation with ECL western blotting substrate (Pierce Biotechnology) according to the manufacturer's conditions, bands were visualized using a Fuji Medical Film Processor FPM-100A (Fuji Photo, Tokyo, Japan).

\section{Resistin ELISA}

Resistin concentrations in conditioned media of transfected 3T3-L1 adipocytes and cell lysates were determined by ELISA (Biovendor Medical Laboratory, Brno, Czech Republic) following instructions from the manufacturer. Absorbance was read at $450 \mathrm{~nm}$ in a Wallac Victor ${ }^{2}$ Multilabel Plate Reader (Perkin Elmer). The amount of measured resistin was corrected for transfection efficiency based on the EGFP measurements and total amount of protein by BCA protein assay. The relative levels of mutant protein was compared with WT levels (set at 100\%) by a one-sample t-test (SPSS, Inc., Version 15.0). Plasma resistin levels in blood samples were also measured by ELISA. Each sample was measured in duplicate in three different experiments. Mean values were compared using a one-way ANOVA with LSD post hoc tests (SPSS, Inc., Version 15.0).

\section{Resistin tissue expression}

We performed a PCR on cDNA from multiple human tissues (Clontech) to examine resistin expression differences. cDNA from five tissues (lung, skeletal muscle, small intestine, and prostate) was compared with adipose tissue (PrimerDesign, Southampton, UK) as a positive control. We also included cDNA from the proband and his parents (originating from RNA extracted from blood). All samples were amplified in a $25 \mu \mathrm{l}$ reaction volume with GoTaq polymerase according to the manufacturer's protocol (Promega). Primers used for resistin were $5^{\prime}$-cTggggcTgTTggTgTcT-3' and $5^{\prime}$-cTggcAgTgAcATgTggTcT- $3^{\prime}$. GAPDH was amplified as internal control using following primers: 5'-TgccAAATATgATgAcATcAAgAA-3' and $5^{\prime}$-ggAgTgggTgTcgcTgTTg-3'. The PCR was paused after $22,26,30$, and 34 cycles to remove $5 \mu \mathrm{l}$ of product from the wells. To quantify the expression, $5 \mu \mathrm{l}$ of PCR product was loaded onto a $1 \%$ agarose gel stained with ethidium bromide.

\section{Results}

\section{Mutation analysis}

We recruited two populations of obese individuals: one cohort of 81 morbidly obese adults (mean BMI= $47.8 \pm 0.5 \mathrm{~kg} / \mathrm{m}^{2}, 21-69$ years) and a cohort of 263 overweight/obese children and adolescents (mean $\mathrm{BMI}=32.8 \pm 0.4 \mathrm{~kg} / \mathrm{m}^{2}, 0-20$ years). Characteristics of the patient populations are shown in Table 1 .

Several known polymorphisms were identified in all study populations (rs3219177, rs12981326, rs1042265, rs3745368, rs3745369, and rs3833230; data not shown).

Mutation analysis of the coding region of the RETN gene revealed no coding mutations in the adult cohort. One 34-year-old female $\left(\mathrm{BMI}=43.6 \mathrm{~kg} / \mathrm{m}^{2}\right)$ was found to carry an intronic variation, IV3-61 C/A. Screening of resistin in the population of children and adolescents identified two heterozygous variations in the $3^{\prime}$-UTR, one heterozygous synonymous coding variation, and one heterozygous missense mutation; one male adolescent (20 years old) with a BMI of $50.6 \mathrm{~kg} / \mathrm{m}^{2}$ carried a $3^{\prime}$-UTR $+100 \mathrm{~A} / \mathrm{G}$ variation; and two patients harbored a 3'-UTR +87 G/A variant: one 19-year-old boy with a BMI of $30.2 \mathrm{~kg} / \mathrm{m}^{2}$ and one 8 -year-old boy with a BMI of $28.7 \mathrm{~kg} / \mathrm{m}^{2}$, which equals obesity at this young age (based on the Flemish Growth Charts (32)). We also found a T73T variation in a 13-year-old boy $(\mathrm{BMI}=33.37)$. Furthermore, we identified a heterozygous C78S mutation in a 20-year-old Caucasian male with severe obesity $\left(B M I=39.7 \mathrm{~kg} / \mathrm{m}^{2}\right)$. Clinical characteristics of all mutation and variation carriers are shown in Table 2. Screening of our control population identified the $3^{\prime}$-UTR +87 G/A variation in one lean female $\left(B M I=19.6 \mathrm{~kg} / \mathrm{m}^{2}\right)$. None of the other variations were identified in control subjects.

\section{Clinical characteristics of $\mathrm{C78S}$ carriers}

The C78S mutation is the first missense mutation reported in resistin. This mutation was found in a severely obese, insulin-resistant male with a BMI of 39.7 at 20 years of age (weight $=128.6 \mathrm{~kg}$, height $=1.80 \mathrm{~m}$ ). The proband reported that he had longstanding obesity since childhood, although he was born with a normal birth weight. He has been enrolled in a weight management program and was considered to be a good weight loss respondent. With a classical life style intervention program in addition to treatment with orlistat, he was able to lose $18 \mathrm{~kg}$ over 4 months. However, he suffered from progressive weight regain after withdrawal of dietary measures. At the age of 28 , the proband weighed $141.6 \mathrm{~kg}\left(\mathrm{BMI}=43.7 \mathrm{~kg} / \mathrm{m}^{2}\right)$. Major metabolic features of the proband and his mother are shown in Table 3.

The C78S mutation was found to be inherited from his obese, insulin-resistant mother $\left(\mathrm{BMI}=31.9 \mathrm{~kg} / \mathrm{m}^{2}\right)$. 
Table 2 Clinical characteristics of variation/mutation carriers. Body mass index (BMI) z-scores are based on Flemish Growth Chart data (30).

\begin{tabular}{|c|c|c|c|c|c|c|c|}
\hline Variation/mutation & Age (years) & Sex & Weight (kg) & Height (m) & BMI $\left(\mathrm{kg} / \mathrm{m}^{2}\right)$ & BMI z-score & Weight class \\
\hline IV3-61 C/A & 34 & $F$ & 143.0 & 1.81 & 43.6 & - & Obesity \\
\hline T73Т & 13 & M & 102.2 & 1.75 & 33.4 & +2.4 & Obesity \\
\hline \multirow[t]{2}{*}{ C78S } & 20 & $M$ & 128.6 & 1.80 & 39.7 & +3.2 & Obesity \\
\hline & 49 & $\mathrm{~F}$ & 85.8 & 1.64 & 31.9 & - & Obesity \\
\hline \multirow[t]{3}{*}{$3^{\prime}$-UTR + $87 \mathrm{G} / \mathrm{A}$} & 8 & M & 69.0 & 1.55 & 28.7 & +2.8 & Obesity \\
\hline & 19 & M & 95.6 & 1.78 & 30.2 & +2.2 & Obesity \\
\hline & 22 & $\mathrm{~F}$ & 1.68 & 55.4 & 19.6 & - & Normal weight \\
\hline $3^{\prime}-$ UTR + $100 \mathrm{~A} / \mathrm{G}$ & 20 & M & 186.7 & 1.92 & 50.6 & +3.7 & Obesity \\
\hline
\end{tabular}

$F$, female; $M$, male.

She was reported to suffer from hypercholesterolemia and high blood pressure by her family doctor. Furthermore, she has an impaired fasting glucose with an elevated $\mathrm{HbAlc}$ suggestive for disturbed glucose tolerance (Table 3 ). His father was also morbidly obese $\left(\mathrm{BMI}=42.5 \mathrm{~kg} / \mathrm{m}^{2}\right)$ but did not carry a mutation in resistin. He also had increased HOMA-IR but showed normal fasting glucose levels (Table 3). Screening of $M C 4 R$ did not identify any additional mutations.

\section{mRNA expression of mutant and WT resistin}

To confirm that the C78S mutation in resistin does not influence resistin mRNA expression, we isolated RNA from 3T3-L1 cell cultures and performed RT-PCR. We were able to demonstrate that the C78S mutation does not impair absolute mRNA expression of resistin. Sequencing of cDNA confirmed that the isolated mRNA harbors the C78S mutation (Fig. 1A-C). Quantitative analysis showed no significant difference in expression levels between $\mathrm{WT}$ and mutant resistin $(P>0.05)$.

Furthermore, we also studied mRNA levels of resistin in blood from the proband and his parents. We found

Table 3 Biochemical characterization of the mutation carriers.

\begin{tabular}{llll}
\hline Parameter & Proband & Mother & Father \\
\hline Age (years) & 20 & 49 & 52 \\
Glucose $(\mathrm{mmol} / \mathrm{l})$ & 4.22 & 6.33 & 5.06 \\
Insulin $(\mu \mathrm{U} / \mathrm{ml})$ & 25 & 27.2 & 18.1 \\
C-peptide $(\mathrm{nmol} / \mathrm{l})$ & 0.53 & 1.76 & 1.43 \\
HOMA-IR & 4.7 & 7.6 & 4.1 \\
HbA1c $(\%)$ & $\mathrm{ND}$ & 6.3 & $\mathrm{ND}$ \\
$\gamma$-GT $(\mathrm{U} / \mathrm{l})$ & 23 & 38 & $\mathrm{ND}$ \\
Cholesterol $(\mathrm{mg} / \mathrm{dl})$ & 210 & 248 & 236 \\
HDL cholesterol $(\mathrm{mg} / \mathrm{dl})$ & 45 & 56 & 46 \\
LDL cholesterol $(\mathrm{mg} / \mathrm{dl})$ & 138 & 161 & 148 \\
Triglycerides $(\mathrm{mg} / \mathrm{dl})$ & 136 & 155 & 209 \\
Uric acid $(\mathrm{mg} / \mathrm{dl})$ & 7.1 & 5.9 & $\mathrm{ND}$ \\
CRP $(\mathrm{mg} / \mathrm{dl})$ & $\mathrm{ND}$ & 1.24 & 0.39 \\
\hline
\end{tabular}

CRP, C-reactive protein; $\gamma$-GT, $\gamma$-glutamyl-transpeptidase; HDL, highdensity lipoprotein; HOMA-IR, homeostatic model assessment of insulin resistance; LDL, low-density lipoprotein; ND, not determined. HOMA-IR is calculated as (insulin $(\mu \mathrm{U} / \mathrm{ml}) \times$ glucose $(\mathrm{mmol} / \mathrm{l})) / 22.5$ with 1 as a reference value for normal insulin sensitivity. that both mutation carriers showed expression of resistin. Sequencing of cDNA revealed that both WT and mutant mRNA were present (Fig. 1D).

\section{Analysis of mutant and WT resistin protein}

Differentiated 3T3-L1 adipocytes were transfected with WT or mutant human resistin. To confirm proper differentiation to adipocytes, we stained 3T3-L1 cells with Oil Red O for every experiment. Differentiation was always present (data not shown).

We investigated by western blotting whether the mutant protein is expressed in differentiated 3T3-L1 adipocytes. We found that WT resistin was present in cell culture medium of transfected cells (Fig. 2) but was undetectable in cell lysates (data not shown). For cells transfected with mutant resistin, we could not detect the protein in medium nor in cell lysates (Fig. 2). In cells transfected with both WT and mutant resistin, we were only able to identify a faint band at about $12.5 \mathrm{kDa}$ in medium (Fig. 2). These results suggest that the mutation might cause impaired secretion of the protein. Furthermore, we found no evidence for intracellular accumulation of mutant protein. Some aspecific banding remains at 10 and $15 \mathrm{kDa}$, which we suspect to represent mouse resistin or 'resistin-like molecule' (RELM) proteins as these are highly related to resistin. These additional bands also show that equal loading was present in all lanes.

We performed an ELISA to confirm these initial results. The concentration of WT or mutant human resistin was determined in the cell culture medium and cell lysates by ELISA $24 \mathrm{~h}$ after transfection. We used a human resistin-specific ELISA, which shows no crossreactivity with mouse protein; therefore, we are confident that our results only represent human resistin levels. After correction for transfection efficiency and total amount of protein, we found that the relative amount of mutant resistin secreted in the cell culture medium was significantly reduced compared with secretion of the WT protein. The relative levels of mutant resistin in medium were 100-fold lower than the WT levels $\left(P=4.87 \times 10^{-6}\right.$; Fig. $\left.3 \mathrm{~A}\right)$. When we co-transfected cells with equimolar amounts of WT and mutant resistin, we found that the relative level of 
A

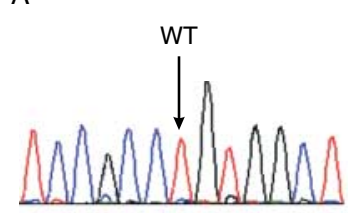

T C CGC C T G T G G C T
B

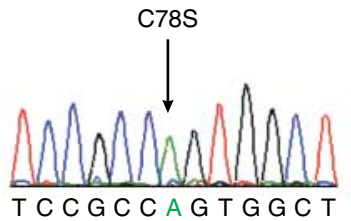

C

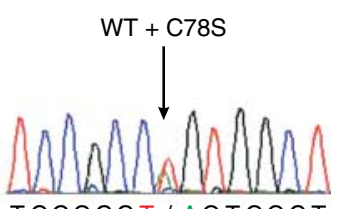

TCCGCCT / AGTGGCT
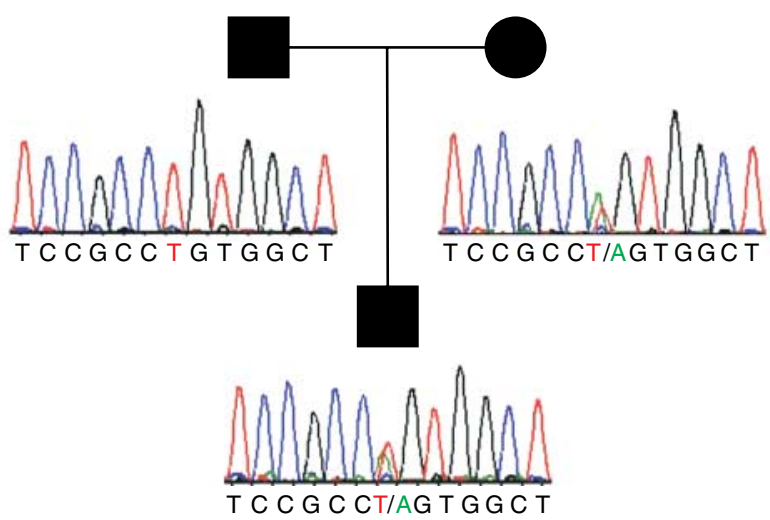

Figure 1 Detection of resistin mRNA expression. (A-C) Detection of resistin mRNA expression in transfected 3T3-L1 cells: mRNA was isolated from 3T3-L1 adipocytes transfected with empty pCMV6-XL4 expression vector, pCMV6-XL4 with WT resistin, pCMV6XL4 with mutant resistin, or a combination of both. Cells transfected without DNA or without application of the electroporation were used as negative controls. RT-PCR was performed and resulting products were sequenced. Electropherograms are shown for cells transfected with WT RETN (A), mutant RETN (B), or a combination of both (C). (D) Detection of resistin mRNA expression in plasma from the proband and his parents: RNA was isolated from blood collected in PAXgene Blood RNA Tubes using the PAXgene Blood RNA kit RT-PCR was performed and the resulting PCR products were sequenced. Electropherograms showing the resistin sequence is shown from the proband, his mother who also carries the mutation and his WT father. secreted resistin was about half of the level seen in cells transfected with WT protein $\left(P=2.048 \times 10^{-4}\right.$; Fig. 3A).

When comparing WT and mutant levels in cell lysates (corrected for transfection efficiency and total amount of protein), it became clear that the amount of intracellularly stored mutant resistin was also lower than the amount of intracellular WT resistin (tenfold lower relative levels, $P=0.007$; Fig. $3 \mathrm{~B}$ ). In cells expressing WT and mutant resistin together, a reduction in intracellular resistin levels was observed, but this difference was not statistically significant $(P=0.451$; Fig. 3B). Together, these results suggest that the mutant resistin is degraded, most likely due to misfolding.

\section{Analysis of plasma resistin in patients and controls}

Plasma resistin levels were measured by ELISA in the proband, his parents, and three lean control individuals (Table 4). We found that no difference in resistin levels was present between the mutation carriers, the lean controls, and the obese father carrying WT resistin $(P=0.596)$. Post hoc comparisons also showed no difference in plasma levels between the lean controls and the mutation carriers $(P=0.598)$. Furthermore, the resistin plasma levels in the WT obese father did not differ from resistin concentrations in the mutation carriers $(P=0.590)$ or the lean controls $(P=0.329)$.

\section{Resistin tissue expression}

Because of the discrepancy between resistin levels in vitro (3T3-L1 adipocytes) and plasma, we decided to compare resistin expression in multiple human tissues using a semi-quantitative PCR. We found that resistin expression is highest in lung, followed by adipose tissue as expected (Fig. 4).

\section{Discussion}

Resistin is considered as one of the most controversial adipokines to date. In mice, it is now accepted that this protein is expressed in adipocytes and has a role in linking obesity and type 2 diabetes (33). However, in

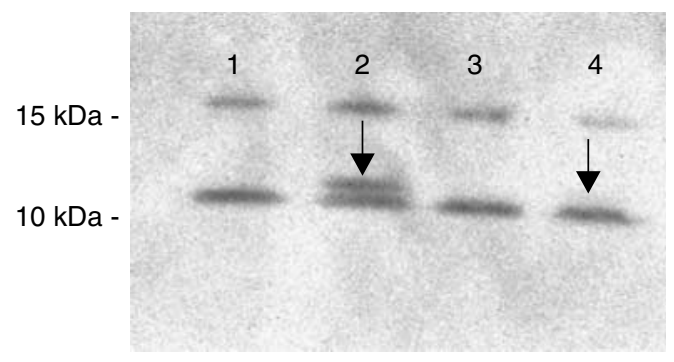

Figure 2 Detection of resistin protein in conditioned medium by western blot. Differentiated 3T3-L1 adipocytes were co-transfected with a WT or mutant resistin containing expression vector or a combination of both and a pEGFP-N1 expression vector to correct for transfection efficiency. Conditioned media and lysates were collected $24 \mathrm{~h}$ after transfection. Resistin was detected by western blot by incubation with polyclonal rabbit anti-resistin antibody followed by goat anti-rabbit IgG HRP conjugate. A clear band representing resistin is visible in cells transfected with WT and a faint band is also seen in cells transfected with both WT and mutant vector (indicated with an arrow). Aspecific bands probably representing mouse RETN or RELM family members are visible at 10 and $15 \mathrm{kDa}$. Lane 1, cells transfected with empty pCMV6-XL4 expression vector. Lane 2 , cells transfected with WT resistin. Lane 3, cells transfected with mutant resistin. Lane 4, cells transfected with both WT and mutant resistin. 

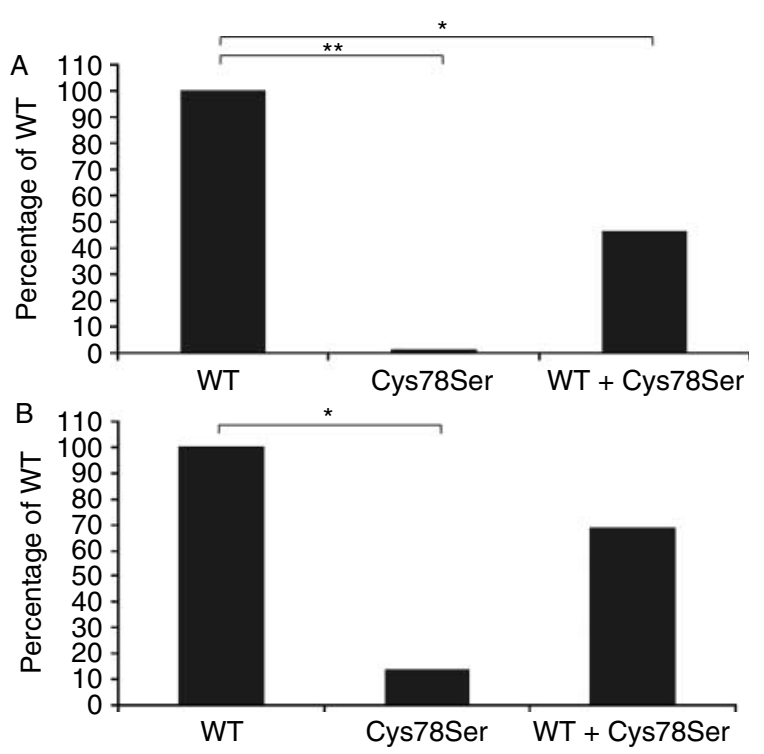

Figure 3 Relative amount of WT or mutant resistin present in cell culture medium and cell lysates of transfected cells. Differentiated 3T3-L1 adipocytes were co-transfected with a WT or mutant resistin containing expression vector or a combination of both and a pEGFP-N1 expression vector to correct for transfection efficiency. Conditioned media and lysates were collected $24 \mathrm{~h}$ after transfection and the amount of resistin was measured by ELISA. The amount of secreted resistin was corrected for transfection efficiency by EGFP measurements and for total amount of protein by BCA measurement on cell lysates. The amount of resistin relative to WT is given. Differences between constructs were calculated by $t$-tests. (A) Relative amount of resistin present in conditioned media. ${ }^{\star} P=2.048 \times 10^{-4} ;{ }^{\star \star} P=4.87 \times 10^{-6}$. (B) Relative amount of resistin present in cell lysates. ${ }^{*} P=0.007$.

humans, much more debate exists about its expression and possible function. First of all, it is not clear whether resistin can be considered to be an adipokine as most reports now agree that resistin is expressed in mononuclear cells and not adipocytes $(8,9)$. Although, in obesity, adipose tissue is infiltrated by macrophages and may as such secrete resistin $(10,11)$. Reports linking the protein to obesity and type 2 diabetes have also been conflicting (20-23). Furthermore, recently, it was suggested that resistin may have an important function in inflammation (34-36).

In this study, we aimed to help clarify the role of resistin in obesity by undertaking a mutation analysis of the gene. We identified two variants in the $3^{\prime}$-UTR: a synonymous coding variant and one intronic variation. One of these (the $3^{\prime}$-UTR +87 G/A variant) was found both in obese and in lean individuals, indicating that this variant is not causative for the obesity. Despite the fact that we were unable to find the remaining ones in our control cohort, we do not expect them to have a functional effect, although this cannot be formally excluded at this point.

More interestingly, we identified the first missense mutation in resistin. The C78S mutation was found in a 20-year-old male with severe obesity and IR.
Re-investigation of the proband at age 28 showed that he was still morbidly obese $\left(\mathrm{BMI}=43.7 \mathrm{~kg} / \mathrm{m}^{2}\right)$. We found that the mutation was inherited from his mother who is also obese and insulin resistant. However, this is not very indicative since his father is obese and insulin resistant as well. Although, this does not exclude that the mutation may cause the obesity seen in the proband, as obesity has a very complex etiology. Furthermore, we found that the phenotype of the mutation carriers is worse than that of the WT father, as they show higher HOMA-IR values and the mother also suffers from impaired fasting glucose.

We believe it to be possible that the morbid obesity of the proband could be due to the resistin mutation in combination with other genetic and/or environmental factors. Screening of the MC4R gene, responsible for most monogenic obesity to date, showed no additional mutations in the proband. Further screening of other functional candidate genes could be performed to potentially identify additional genetic components of the proband's obesity phenotype.

A C78S mutation can be expected to have a major effect on the protein. A cysteine residue can have important functions through its involvement in the formation of disulfide bridges. C78 of resistin is located in the highly conserved cysteine-rich C-terminus of resistin. All members of the resistin-like family of proteins (resistin, RELM- $\alpha$, RELM- $\beta$, and RELM- $\gamma$ ) share a common C-terminus domain with a high number of cysteines of which the spacing is invariant $\left({ }^{1} \mathrm{C}-\mathrm{X}_{11^{-}}{ }^{2} \mathrm{C}-\mathrm{X}_{8}{ }^{-3} \mathrm{C}-\mathrm{X}-{ }^{4} \mathrm{C}-\mathrm{X}_{3}-{ }^{5} \mathrm{C}-\mathrm{X}_{10}{ }^{6} \mathrm{C}-\mathrm{X}^{7}{ }^{7} \mathrm{C}-\mathrm{X}^{8}{ }^{8} \mathrm{C}-\mathrm{X}_{9}{ }^{-9} \mathrm{C}-{ }^{10} \mathrm{C}\right)$ $(1,2)$. C78 is the 5 th cysteine of this motif and is most probably involved in the formation of a disulfide bridge (37). Loss of a disulfide bridge is predicted to have large consequences on the tertiary structure of the protein. By use of the POLYPHEN prediction program (38), we also found that this mutation is probably damaging to the protein structure. Furthermore, this residue is highly conserved between species and homologous genes (Fig. 5).

Functional characterization of the C78S mutation showed that the mutant protein was not secreted in vitro, although mRNA expression was not different from WT. These data suggest that the mutant protein is degraded before it enters the secretory pathway. On the

Table 4 Comparison of plasma resistin levels between lean control individuals, mutation carriers, and obese father carrying WT resistin. Mean \pm S.E.M. is given for age, BMI, and resistin concentration, except for the obese father for age and BMI.

\begin{tabular}{lcccl}
\hline & $\begin{array}{c}\text { Lean } \\
\text { controls }\end{array}$ & $\begin{array}{c}\text { Mutation } \\
\text { carriers }\end{array}$ & $\begin{array}{c}\text { WT obese } \\
\text { father }\end{array}$ & \multicolumn{1}{c}{$\boldsymbol{P}$ value } \\
\hline$n$ & 3 & 2 & 1 & - \\
Age (years) & $25 \pm 1$ & $38.5 \pm 5$ & 52 & $5.6 \times 10^{-5}$ \\
$\mathrm{BMl}\left(\mathrm{kg} / \mathrm{m}^{2}\right)$ & $22.1 \pm 0.9$ & $37.8 \pm 2.6$ & 42.5 & $1.16 \times 10^{-6}$ \\
Resistin $(\mathrm{ng} / \mathrm{ml})$ & $4.26 \pm 0.06$ & $4.10 \pm 0.37$ & $3.89 \pm 0.04$ & 0.596 \\
\hline
\end{tabular}

$P$ values are calculated by one-way ANOVA. 


\begin{tabular}{|c|c|c|c|c|c|c|c|c|c|c|c|}
\hline mResistin & 76 & C & $S$ & C & $\mathrm{G}$ & $S$ & A & C & $\mathrm{G}$ & $S$ & W \\
\hline hResistin & 72 & C & $\mathrm{T}$ & $\mathrm{C}$ & $\mathrm{G}$ & $S$ & $A$ & C & $\mathrm{G}$ & $S$ & W \\
\hline mRELM $\alpha$ & 76 & C & A & C & $\mathrm{G}$ & $F$ & A & C & $\mathrm{G}$ & $S$ & W \\
\hline rRELM $\alpha$ & 76 & C & $S$ & C & $\mathrm{G}$ & $F$ & $A$ & C & $\mathrm{G}$ & $S$ & W \\
\hline mRELM $\beta$ & 70 & C & A & $\mathrm{C}$ & $\mathrm{G}$ & $Y$ & $G$ & C & $\mathrm{G}$ & $S$ & W \\
\hline hRELM $\beta$ & 76 & C & $A$ & $\mathrm{C}$ & $\mathrm{G}$ & $Y$ & $G$ & C & $\mathrm{G}$ & $S$ & W \\
\hline
\end{tabular}

Figure 4 Conservation of the mutated cysteine residue between RELM family members. Protein sequences of different RELM family members surrounding the mutated cysteine are shown. The residue corresponding to human Cys78 is indicated by an arrow. $m$, mouse; $h$, human; $r$, rat.

other hand, it is also possible that the mutant protein has such an aberrant tertiary structure that it cannot be detected by the antibody used in the ELISA. However, we also performed a western blot with another antibody generated against resistin, and this antibody was also not able to identify any mutant resistin in the medium of transfected cells. This suggests that the observed effect is not caused by a failure of the antibody. Furthermore, we found that mutant resistin was detected in cell lysates, albeit at a much lower level than in WT cells. This strengthens our belief that mutant resistin is not secreted and demonstrates that there is no intracellular accumulation of the mutant protein as this would cause a much higher intracellular level than observed in WT cells. We therefore believe that the mutant protein is degraded as we were able to identify mutant resistin mRNA expression.

As the function of resistin is not clear at the moment, it is difficult to predict how the C78S mutation may impair this function and consequently may cause the observed obesity. However, as Kim et al. $(3,4)$ have reported that WT resistin is able to inhibit adipocyte conversion in 3T3-L1 cells in vitro, we hypothesize that due to the large reduction in resistin levels, adipocytes could differentiate uncontrollably. This loss of inhibition could lead to an excess amount of adipose tissue and associated obesity. However, this hypothesis has yet to be confirmed by in vitro experiments. At this point, we were not able to confirm the in vitro data of decreased extracellular concentration in the plasma of our patients. Based on our in vitro data, we speculate that mutation carriers have a $50 \%$ reduction in resistin levels in adipose tissue, although this is not reflected by measured plasma levels. Several studies have, however, already indicated that resistin blood levels do not correlate to resistin adipose tissue levels (39-41). Therefore, we suspect that a reduction in resistin levels may be present in the adipose tissue, having a local effect on adipogenesis. This hypothesis would need confirmation by obtaining adipose tissue biopsies from mutation carriers, obese individuals, and lean persons. Alternatively, it would also be possible that another source of resistin may exist that could produce a compensatory effect, although we are currently not aware of such a source. Furthermore, we cannot rule out that the lack of correlation between adipose tissue and plasma levels may be due to methodological limitations.

When determining resistin expression by semiquantitative PCR, we found that highest expression is present in lung as reported before (8). Expression in adipose tissue was also clearly present and was comparable to the expression found in blood from the proband and his parents.

Further experiments directly proving that the present mutation causes a reduction in the inhibitory function of resistin on adipogenesis are difficult. It would be possible to culture pre-adipocytes in conditioned medium to study the impact of secreted resistin on adipogenesis. However, as the present mutation causes degradation of the mutated protein, this would result in an experiment comparing normal levels of WT resistin to reduced levels of WT resistin. This would be comparable to the experiments performed by Kim et al. (4) with a dominant inhibitory form of resistin (ADSF$\mathrm{hFc}$ ). In these studies, transgenic mice overexpressing ADSF-hFc were created and these animals display enhanced adipogenesis (4). These mice show an

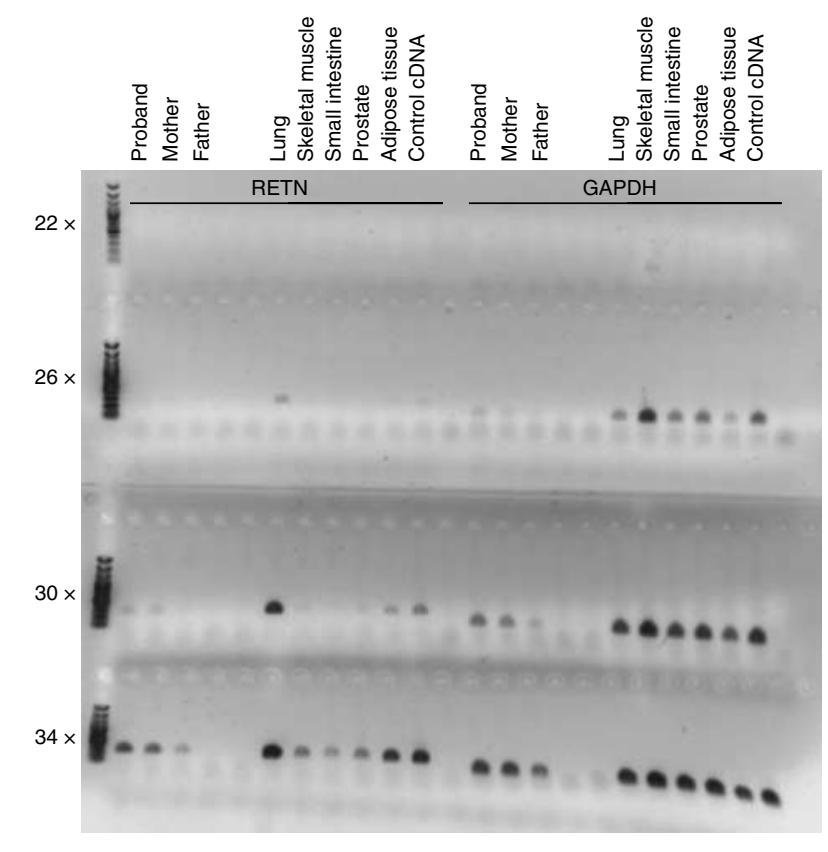

Figure 5 Resistin expression in multiple human tissues. cDNA from different human tissues as well as from blood from the proband and his parents was amplified by PCR. Control CDNA originating from a variety of human tissues is also included as positive control sample. To quantify the expression of RETN at different time points during amplification (number of cycles is indicated on the left), $5 \mu \mathrm{l}$ of PCR product was loaded onto a $1 \%$ agarose gel stained with ethidium bromide. GAPDH expression is shown as internal control. 
increase in body weight and adiposity with enlarged adipocyte size and higher expression of adipocyte markers. In vitro data showed that conditioned media containing the dominant inhibitory resistin prevented the inhibitory effect of normal resistin on adipocyte differentiation of 3T3-L1 cells (4). Another strategy could be to repeat the our experiments in a human preadipocyte cell line as our current experiments were all performed in 3T3-L1 cells which are of mice origin.

Further evidence strengthening our belief that a mutation in resistin may play a role in the pathogenesis of obesity comes from the leptin-resistin double knockout mouse $(o b / o b$-RKO). Deletion of resistin from mice lacking leptin ( $o b / o b$ mice) dramatically worsens their obese phenotype. The increase in body weight was not caused by a further increase in food intake, but by lowering energy expenditure. The increase in body weight was paraleled by a significant increase in percent body fat in $o b / o b$-RKO mice compared with $o b / o b$ mice $(42,43)$.

Together these studies support our hypothesis that resistin plays a role in controlling the amount of adipose tissue. A mutation in the resistin gene could, therefore, ablate this function and may cause obesity as observed in our proband. However, as there has been large debate about the homology of human resistin to rodent resistin and its function, we cannot conclude at the moment that the C78S mutation is the definitive cause of obesity. However, the finding of a mutation in an obese proband and his obese mother proves that a possible function of the protein in obesity may not be dismissed. Molecular characterization of the mutant protein indicates that the mutation has an effect and most likely leads to degradation of the protein. Further functional studies on WT and mutant resistin will be necessary to further elucidate the role of this effect in the pathogenesis of obesity.

As we only identified one mutation in a single proband and his mother, it is difficult to firmly conclude that resistin mutations might lead to obesity. Therefore, identification of other mutation carriers would be necessary to confirm the causality of resistin mutations in the development of obesity and to further study the phenotype associated with these mutations.

\section{Declaration of interest}

The authors declare that there is no conflict of interest that could be perceived as prejudicing the impartiality of the research reported.

\section{Funding}

This study was supported by a grant (G.0028.05) from the 'Fund for Scientific Research Flanders' (FWO-Vlaanderen) and a BOF grant from the University of Antwerp, both to W Van Hul and to L F Van Gaal. $S$ Beckers is a post-doctoral fellow of the "Fund for Scientific Research Flanders' (FWO-Vlaanderen). D Zegers holds a specialization scholarship from the 'Institute for the Promotion of Innovation through Science and Technology in Flanders (IWT-Vlaanderen)'.

\section{Author contribution statement}

S Beckers and W Van Hul researched data, contributed to discussion, and wrote the manuscript. D Zegers, F de Freitas, A Verrijken, F Peiffer, S L Verhulst, G Massa, I L Mertens, and K N Desager researched data and reviewed manuscript. A V Peeters contributed to discussion and reviewed manuscript. L F Van Gaal researched data, contributed to discussion, and reviewed/edited manuscript.

\section{References}

1 Steppan CM, Bailey ST, Bhat S, Brown EJ, Banerjee RR, Wright CM, Patel HR, Ahima RS \& Lazar MA. The hormone resistin links obesity to diabetes. Nature 2001409 307-312. (doi:10.1038/ 35053000)

2 Holcomb IN, Kabakoff RC, Chan B, Baker TW, Gurney A, Henzel W, Nelson C, Lowman HB, Wright BD, Skelton NJ, Frantz GD, Tumas DB, Peale FV Jr, Shelton DL \& Hebert CC. FIZZ1, a novel cysteine-rich secreted protein associated with pulmonary inflammation, defines a new gene family. EMBO Journal 2000 19 4046-4055. (doi:10.1093/emboj/19.15.4046)

$3 \mathrm{Kim}$ KH, Lee K, Moon YS \& Sul HS. A cysteine-rich adipose tissuespecific secretory factor inhibits adipocyte differentiation. Journal of Biological Chemistry 2001276 11252-11256. (doi:10.1074/jbc. C100028200)

4 Kim KH, Zhao L, Moon Y, Kang C \& Sul HS. Dominant inhibitory adipocyte-specific secretory factor (ADSF)/resistin enhances adipogenesis and improves insulin sensitivity. PNAS $2004 \mathbf{1 0 1}$ 6780-6785. (doi:10.1073/pnas.0305905101)

5 Muse ED, Obici S, Bhanot S, Monia BP, McKay RA, Rajala MW, Scherer PE \& Rossetti L. Role of resistin in diet-induced hepatic insulin resistance. Journal of Clinical Investigation 2004 114 232-239. (doi:10.1172/JCI200421270)

6 Banerjee RR, Rangwala SM, Shapiro JS, Rich AS, Rhoades B, Qi Y, Wang J, Rajala MW, Pocai A, Scherer PE, Steppan CM, Ahima RS, Obici S, Rossetti L \& Lazar MA. Regulation of fasted blood glucose by resistin. Science 2004303 1195-1198. (doi:10.1126/science. 1092341)

7 Satoh H, Nguyen MT, Miles PD, Imamura T, Usui I \& Olefsky JM. Adenovirus-mediated chronic "hyper-resistinemia" leads to in vivo insulin resistance in normal rats. Journal of Clinical Investigation 2004114 224-231. (doi:10.1172/JCI200420785)

8 Patel L, Buckels AC, Kinghorn IJ, Murdock PR, Holbrook JD, Plumpton C, Macphee CH \& Smith SA. Resistin is expressed in human macrophages and directly regulated by PPAR gamma activators. Biochemical and Biophysical Research Communications 2003300 472-476. (doi:10.1016/S0006-291X(02)02841-3)

9 Fain JN, Cheema PS, Bahouth SW \& Lloyd Hiler M. Resistin release by human adipose tissue explants in primary culture. Biochemical and Biophysical Research Communications 2003300 674-678. (doi:10.1016/S0006-291X(02)02864-4)

10 Weisberg SP, McCann D, Desai M, Rosenbaum M, Leibel RL \& Ferrante AW Jr. Obesity is associated with macrophage accumulation in adipose tissue. Journal of Clinical Investigation 2003112 1796-1808. (doi:10.1172/JCI19246)

11 Xu H, Barnes GT, Yang Q, Tan G, Yang D, Chou CJ, Sole J, Nichols A, Ross JS, Tartaglia LA \& Chen H. Chronic inflammation in fat plays a crucial role in the development of obesity-related insulin resistance. Journal of Clinical Investigation 2003112 1821-1830. (doi:10.1172/JCI19451)

12 Azuma K, Katsukawa F, Oguchi S, Murata M, Yamazaki H, Shimada A \& Saruta T. Correlation between serum resistin level and adiposity in obese individuals. Obesity Research 200311 997-1001. (doi:10.1038/oby.2003.137)

13 Degawa-Yamauchi M, Bovenkerk JE, Juliar BE, Watson W, Kerr K, Jones R, Zhu Q \& Considine RV. Serum resistin (FIZZ3) protein is increased in obese humans. Journal of Clinical Endocrinology and Metabolism 200388 5452-5455. (doi:10.1210/jc.2002021808) 
14 Silha JV, Krsek M, Skrha JV, Sucharda P, Nyomba BL \& Murphy LJ. Plasma resistin, adiponectin and leptin levels in lean and obese subjects: correlations with insulin resistance. European Journal of Endocrinology 2003 149 331-335. (doi:10.1530/eje.0.1490331)

15 Lee JH, Chan JL, Yiannakouris N, Kontogianni M, Estrada E, Seip R, Orlova C \& Mantzoros CS. Circulating resistin levels are not associated with obesity or insulin resistance in humans and are not regulated by fasting or leptin administration: cross-sectional and interventional studies in normal, insulin-resistant, and diabetic subjects. Journal of Clinical Endocrinology and Metabolism 200388 4848-4856. (doi:10.1210/jc.2003-030519)

16 Beckers S, Peeters AV, Freitas F, Mertens IL, Hendrickx JJ, Van Gaal LF \& Van Hul W. Analysis of genetic variations in the resistin gene shows no associations with obesity in women. Obesity 200816 905-907. (doi:10.1038/oby.2007.131)

17 Sentinelli F, Romeo S, Arca M, Filippi E, Leonetti F, Banchieri M, Di Mario U \& Baroni MG. Human resistin gene, obesity, and type 2 diabetes: mutation analysis and population study. Diabetes 2002 51 860-862. (doi:10.2337/diabetes.51.3.860)

18 Cho YM, Youn BS, Chung SS, Kim KW, Lee HK, Yu KY, Park HJ, Shin HD \& Park KS. Common genetic polymorphisms in the promoter of resistin gene are major determinants of plasma resistin concentrations in humans. Diabetologia $2004 \mathbf{4 7}$ 559-565. (doi:10.1007/s00125-003-1319-x)

19 Engert JC, Vohl MC, Williams SM, Lepage P, Loredo-Osti JC, Faith J, Dore C, Renaud Y, Burtt NP, Villeneuve A, Hirschhorn JN, Altshuler D, Groop LC, Despres JP, Gaudet D \& Hudson TJ. $5^{\prime}$ flanking variants of resistin are associated with obesity. Diabetes 200251 1629-1634. (doi:10.2337/diabetes.51.5.1629)

20 Smith SR, Bai F, Charbonneau C, Janderova L \& Argyropoulos G. A promoter genotype and oxidative stress potentially link resistin to human insulin resistance. Diabetes 200352 1611-1618. (doi:10.2337/diabetes.52.7.1611)

21 Pizzuti A, Argiolas A, Di Paola R, Baratta R, Rauseo A, Bozzali M, Vigneri R, Dallapiccola B, Trischitta V \& Frittitta L. An ATG repeat in the $3^{\prime}$-untranslated region of the human resistin gene is associated with a decreased risk of insulin resistance. Journal of Clinical Endocrinology and Metabolism 200287 4403-4406. (doi:10.1210/jc.2002-020096)

22 Ma X, Warram JH, Trischitta V \& Doria A. Genetic variants at the resistin locus and risk of type 2 diabetes in Caucasians. Journal of Clinical Endocrinology and Metabolism 200287 4407-4410. (doi:10.1210/jc.2002-020109)

23 Gouni-Berthold I, Giannakidou E, Faust M, Kratzsch J, Berthold HK \& Krone W. Resistin gene $3^{\prime}$-untranslated region $+62 \mathrm{G} \rightarrow$ A polymorphism is associated with hypertension but not diabetes mellitus type 2 in a German population. Journal of Internal Medicine 2005258 518-526. (doi:10.1111/j.1365-2796.2005. 01566.x)

24 Guo XR, Gong HX, Gao YQ, Fei L, Ni YH \& Chen RH. A mutation in signal peptide of rat resistin gene inhibits differentiation of 3T3-L1 preadipocytes. Acta Pharmacologica Sinica 200425 1705-1711.

25 Hivert MF, Manning AK, McAteer JB, Dupuis J, Fox CS, Cupples LA, Meigs JB \& Florez JC. Association of variants in RETN with plasma resistin levels and diabetes-related traits in the Framingham Offspring Study. Diabetes 200958 750-756. (doi:10.2337/db081339)

26 Onuma H, Tabara Y, Kawamura R, Tanaka T, Ohashi J, Nishida W, Takata Y, Ochi M, Yamada K, Kawamoto R, Kohara K, Miki T, Makino H \& Osawa H. A at single nucleotide polymorphism-358 is required for $\mathrm{G}$ at -420 to confer the highest plasma resistin in the general Japanese population. PLoS ONE 20105 e9718. (doi:10.1371/journal.pone.0009718)

27 Friedewald WT, Levy RI \& Fredrickson DS. Estimation of the concentration of low-density lipoprotein cholesterol in plasma, without use of the preparative ultracentrifuge. Clinical Chemistry $197218499-502$.

28 Matthews DR, Hosker JP, Rudenski AS, Naylor BA, Treacher DF \& Turner RC. Homeostasis model assessment: insulin resistance and beta-cell function from fasting plasma glucose and insulin concentrations in man. Diabetologia 198528 412-419. (doi:10. 1007/BF00280883)

29 Beckers S, Mertens I, Peeters A, Van Gaal L \& Van Hul W. Screening for melanocortin-4 receptor mutations in a cohort of Belgian morbidly obese adults and children. International Journal of Obesity 200630 221-225. (doi:10.1038/sj.ijo.0803126)

30 Vesuna F, Winnard P Jr \& Raman V. Enhanced green fluorescent protein as an alternative control reporter to Renilla luciferase. Analytical Biochemistry 2005342 345-347. (doi:10.1016/j.ab. 2005.04.047)

31 Hellemans J, Mortier G, De Paepe A, Speleman F \& Vandesompele J. qBase relative quantification framework and software for management and automated analysis of real-time quantitative PCR data. Genome Biology 20078 R19. (doi:10.1186/gb-2007-8-2-r19)

32 Roelants M, Hauspie R \& Hoppenbrouwers K. References for growth and pubertal development from birth to 21 years in Flanders, Belgium. Annals of Human Biology 200936 680-694. (doi:10.3109/03014460903049074)

33 Steppan CM \& Lazar MA. The current biology of resistin. Journal of Internal Medicine 2004255 439-447. (doi:10.1111/ j.1365-2796.2004.01306.x)

34 Nagaev I, Bokarewa M, Tarkowski A \& Smith U. Human resistin is a systemic immune-derived proinflammatory cytokine targeting both leukocytes and adipocytes. PLOS ONE 20061 e31. (doi:10. 1371/journal.pone.0000031)

35 Silswal N, Singh AK, Aruna B, Mukhopadhyay S, Ghosh S \& Ehtesham NZ. Human resistin stimulates the pro-inflammatory cytokines TNF-alpha and IL-12 in macrophages by NF-kappa B-dependent pathway. Biochemical and Biophysical Research Communications 2005334 1092-1101. (doi:10.1016/j.bbrc. 2005.06.202)

36 Lehrke M, Reilly MP, Millington SC, Iqbal N, Rader DJ \& Lazar MA. An inflammatory cascade leading to hyperresistinemia in humans. PLoS Medicine 20041 e45. (doi:10.1371/journal. pmed.0010045)

37 Patel SD, Rajala MW, Rossetti L, Scherer PE \& Shapiro L. Disulfidedependent multimeric assembly of resistin family hormones. Science 2004304 1154-1158. (doi:10.1126/science.1093466)

38 Ramensky V, Bork P \& Sunyaev S. Human non-synonymous SNPs: server and survey. Nucleic Acids Research $2002303894-3900$. (doi:10.1093/nar/gkf493)

39 Dostalova I, Kunesova M, Duskova J, Papezova H \& Nedvidkova J. Adipose tissue resistin levels in patients with anorexia nervosa Nutrition 200622 977-983. (doi:10.1016/j.nut.2006.06.006)

40 Dolezalova R, Lacinova Z, Dolinkova M, Kleiblova P, Haluzikova D, Housa D, Papezova H \& Haluzik M. Changes of endocrine function of adipose tissue in anorexia nervosa: comparison of circulating levels versus subcutaneous mRNA expression. Clinical Endocrinology 200767 674-678. (doi:10.1111/j.1365-2265.2007. 02944.x)

41 Dostalova I, Kavalkova P, Haluzikova D, Housova J, Matoulek M \& Haluzik M. The use of microdialysis to characterize the endocrine production of human subcutaneous adipose tissue in vivo. Regulatory Peptides 2009155 156-162. (doi:10.1016/j.regpep. 2009.03.008)

42 Qi Y, Nie Z, Lee YS, Singhal NS, Scherer PE, Lazar MA \& Ahima RS. Loss of resistin improves glucose homeostasis in leptin deficiency. Diabetes 200655 3083-3090. (doi:10.2337/db05-0615)

43 Singhal NS, Patel RT, Qi Y, Lee YS \& Ahima RS. Loss of resistin ameliorates hyperlipidemia and hepatic steatosis in leptin-deficient mice. American Journal of Physiology. Endocrinology and Metabolism 2008295 E331-E338. (doi:10.1152/ajpendo.00577.2007)

Received 1 March 2011

Accepted 25 March 2011 